\title{
THE GENETIC CONTROL OF EAR-EMERGENCE TIME BY CHROMOSOMES 5A AND 5D OF WHEAT
}

\author{
C. N. LAW, A. J. WORLAND and B. GIORGI* \\ Plant Breeding Institute, Trumpington, Cambridge
}

Received 28.vii.75

\begin{abstract}
Summary
Chromosomes 5A and 5D of wheat are important in determining the different responses of winter and spring varieties to vernalisation. Using single chromosome substitution lines in which chromosomes $5 \mathrm{~A}$ and $5 \mathrm{D}$ of the variety Hope replace their homologues in the variety Chinese Spring, single genes having a large effect on the time to ear emergence were located distally on the long-arms of both chromosome 5A and 5D. The similar location of these genes on homoeologous chromosomes suggests that they are duplicate loci resulting from the polyploid nature of wheat. It is likely that the genes on chromosomes $5 \mathrm{~A}$ and 5D are equivalent to $V r n_{1}$ and $V r n_{3}$ respectively, the genes for vernalisation requirement identified in other studies.

Additional variation in the time to ear emergence was found in other substitution lines of chromosomes $5 \mathrm{~A}$ and $5 \mathrm{D}$. It is possible that this variation reflects multiple allelism at the $V r_{1}$ and $V r n_{3}$ loci. Also, by comparing the ear-emergence times of these substitution lines with alien substitutions in which chromosome $5 \mathrm{C}^{u}$ of Aegilops umbellulata replaces either chromosome $5 \mathrm{~A}$ or $5 \mathrm{D}$ of Chinese Spring, it was possible to relate the effects of chromosome $5 \mathrm{~A}$ to those of chromosome 5D.
\end{abstract}

\section{INTRODUGTION}

Gultivated varieties of the bread wheat, Triticum aestivum $(2 n=6 x=42)$ can be divided into two main categories distinguished by their adaptation to different sowing dates and referred to as either winter or spring wheats. As might be expected, autumn sown or winter wheats are usually more resistant to frost damage than spring sown wheats, but combined with this is a second adaptive feature, a requirement for a period of low temperature or vernalisation before floral initiation may take place. This vernalisation requirement prevents the onset of flower development during winter, thereby providing additional protection for the environmentally sensitive floral organs. By contrast, spring wheats have no need for such protection and the vernalisation requirement for this type of wheat is usually small and in some cases, nonexistent.

The genetic control of this polymorphism has been investigated using both aneuploid and conventional analyses. The aneuploid lines of the spring wheat variety, Chinese Spring, have been crossed with a wide range of donor varieties, including examples of both winter and spring wheats, and the chromosomal control of ear-emergence time has been investigated by monosomic analysis (Unrau, 1950; Morrison, 1960; Tsunewaki, 1966; Rajki and Rajki, 1969; Maystrenko, 1973), and by the development of whole chromosome substitution lines (Kuspira and Unrau, 1957; Halloran

* Present address: Laboratorio per le Applicazioni in Agricoltura, Centro di Studi Nucleari dello Casaccia, Rome, Italy. 
and Boydell, 1967; Law, 1968). Although a number of chromosomes have been identified as affecting this character, the major effects have been found to be associated with the chromosomes of homoeologous group 5, particularly chromosomes $5 \mathrm{~A}$ and $5 \mathrm{D}$. These chromosomes have also been shown to carry genes which control the response of plants to vernalisation treatment (Halloran, 1966; Halloran and Boydell, 1967). The genetic control of winter-spring wheat differences is therefore predominantly controlled by the chromosomes belonging to this homoeologous group.

Conventional genetic analyses have also demonstrated that these differences are determined by a relatively few major genes and a number of genes of minor effect. Akerman and Mackey (1949) demonstrated that the difference between Swedish spring and winter wheats was due to a single gene $\left(S_{k}\right)$. Pugsley $(1971,1972)$ extended the analysis further and identified four genes controlling spring-winter habit in a range of wheat varieties.

Although the genes isolated by conventional genetic analysis are almost certainly related to the whole chromosome effects identified by aneuploid analysis, the detailed description of the number and location of genes involved in each of the chromosome differences associated with homoeologous group 5 has still to be carried out. The experiments described in this paper are aimed at providing some of this information.

\section{MAterials AND METHODS}

(i) Substitution lines

The following substitution lines in which representatives of chromosomes $5 \mathrm{~A}$ and $5 \mathrm{D}$ from a range of donor varieties have replaced their homologues in Chinese Spring (CS) were used.

1. CS (Hope 5A) and CS (Hope 5D).

2. CS (Cheyenne 5A) and CS (Cheyenne 5D).

3. CS (Cappelle-Desprez 5A) and CS (Cappele-Desprez 5D).

4. CS (Triticum spelta 5A) and CS (Triticum spelta 5D).

The Hope substitution lines were developed by Dr E. R. Sears, University of Missouri, U.S.A., and the Cheyenne substitutions by Dr R. Morris, University of Nebraska, U.S.A. Both the Cappelle-Desprez and Triticum spelta substitutions were produced at the Plant Breeding Institute by the senior authors.

Two further substitution lines, CS $5 \mathrm{~A}(5 \mathrm{Cu})$ and CS $5 \mathrm{D}(5 \mathrm{Cu})$, in which chromosomes 5A and 5D of CS were replaced by the homoeologous chromosome $5 \mathrm{Cu}^{\mathrm{u}}$ of Aegilops umbellulata, were also used and were developed by $\mathrm{Mr}$ V. Chapman at the Plant Breeding Institute.

\section{(ii) The investigation of the genetics of whole chromosome differences}

The detailed study of whole chromosome differences was carried out on CS (Hope 5D) and CS (Hope 5A) in a series of experiments, following the procedures described by Law $(1966 ; 1967)$. Each of these substitution lines was crossed to CS and separately to the homologous long-armed telocentric lines, CS ditelocentric 5D $\mathrm{D}^{\mathrm{L}}$ and $\mathrm{CS}$ ditelocentric $5 \mathrm{~A}^{\mathrm{L}}$. These hybrids were then backcrossed as pollen parents to the $5 \mathrm{D}$ and $5 \mathrm{~A}$ monosomic lines of CS 
and monosomic and mono-telocentric lines selected by means of chromosome counts of root-tip cells stained in Feulgen.

Each of these selected derivatives carries in the hemizygous condition either the substituted chromosome or its CS homologue or a recombinant chromosome between the two. For the derivatives of the hybrids involving the long-arm telocentric chromosome then the hemizygous complete and telocentric chromosomes could also represent the products of recombination but in this case crossing-over would be restricted to the long arm only.

Depending upon the experiment, the days from sowing to ear emergence were recorded for either the selected monosomic or mono-telocentric plants, or on their selfed progeny, or on the progeny of disomics selected from among these selfed derivatives. In the latter case, the selected disomics carried either the non-recombinant or recombinant chromosome in the homozygous state.

It is by studying the variation amongst these derivatives that estimates of the number of genes affecting ear emergence can be achieved. Also, the derivatives of the hybrids involving a telocentric chromosome can provide information about the location of genes with respect to the centromere.

\section{(iii) Background variation}

An additional crossing procedure used by Law (loc. cit.) was also carried out for the study of CS (Hope 5A). This permits the recognition of genetic differences not associated with the substituted chromosome or its homologue. Both CS (Hope 5A) and CS were crossed to CS monosomic 5A and derivatives selected in the manner already described for the hybrids. The presence of heritable variation within these parental products indicates gene differences in the background.

This method also provides a test of gene locations when the genes being studied are separated by more than 50 map units on the substituted chromosome.

\section{Results}

\section{(i) The investigation of chromosome $5 D$}

In the first experiment, five progeny from each of 96 selected monosomic plants from the cross, CS monosomic $5 \mathrm{D} \times\{\mathrm{CS} \times \mathrm{CS}$ (Hope 5D) $\}$ and 25 selected monosomic and mono-telocentric plants from the cross, CS monosomic $5 \mathrm{D} \times\left\{\mathrm{CSDT} 5 \mathrm{D}^{\mathrm{L}} \times \mathrm{CS}\right.$ (Hope $\left.\left.5 \mathrm{D}\right)\right\}$ were grown in the field during 1969 and their days to ear emergence recorded.

The mean ear-emergence values for those families derived from $\mathrm{CS} \times \mathrm{CS}$ (Hope 5D) segregated to give two distinct classes of 54 early to 42 late, agreeing with the expected $1: 1$ ratio of a single gene $\left(\chi_{\{1\}}^{2}=1 \cdot 50, \mathrm{P}, 0 \cdot 3-0 \cdot 2\right)$. A similar segregation into two classes occurred for the derivatives of CSDT 5D ${ }^{\mathrm{L}} \times$ CS $($ Hope 5D).

These results clearly indicated the presence of a single gene of large effect on the time to ear emergence. However, each of the families was composed of both monosomic and disomic plants, so that chromosome dosage effects could have obscured the segregation of other genes having minor effects on this character. For this reason disomics were selected from the seed obtained 
from each of the families and the progeny of these plants used in a further experiment. This meant that two generations of selfing occurred between the two experiments. Also because of the extreme lateness of many of the lines, several were found difficult to maintain so that some of the lines carrying the allele having a major effect on lateness were not represented in the second experiment.

This was carried out in a controlled environment room under continuous light at a temperature of $18^{\circ} \mathrm{C}$. Each of the 94 lines studied was replicated four times in a randomised block lay-out. Again a clear segregation into two distinct groups was apparent. However, because of replication, it was possible to determine whether the variation within the two groups was heritable or not. The analysis of the variation is given in table 1 and shows that the differences between the lines can be accounted for in terms of a single gene since the residual item in the analysis is non-significant.

\section{TABLE 1}

Analysis of variation of ear emergence for 94 derivatives of CS $\times$ CS (Hope $5 D$ ) and $C S D T 5 D^{L} \times C S($ Hope $5 D)$ grown under continuous light at $18^{\circ} \mathrm{C}$

$\begin{array}{lrrcc}\quad \text { Item } & \text { d.f. } & \text { M.S. } & \text { V.R. } & \text { P } \\ \text { Blocks } & 3 & 79.44 & - & - \\ \text { Early v. late } & 1 & 62725.17 & 2611.37 & <0.001 \\ \text { Residual } & 92 & 30.75 & 1.28 & - \\ \text { Error } & 279 & 24.02 & - & -\end{array}$

The classification of the derivatives of CSDT $5 \mathrm{D}^{\mathrm{L}} \times \mathrm{CS}(\mathrm{Hope} 5 \mathrm{D})$ should permit the arm location of the gene. Only 25 lines were available and the classification of these into early and late as well as ditelocentric or disomic complete is presented in table 2 . The results agree with the expected 1:1 segregation for early versus late $\left(\chi_{\{1\}}^{2}=3 \cdot 24, \mathrm{P} 0 \cdot 10-0 \cdot 05\right)$ and show a significantly low transmission of the telocentric chromosome $\left(\chi_{\{1\}}^{2}=11.56\right.$, $\mathrm{P}<0.001)$. More importantly however the test for linkage is not significant $\left(x_{\{1\}}^{2}=0.04, \mathrm{P} 0.09\right)$ so that there is no direct evidence that the gene affecting ear emergence is located on chromosome 5D.

The two experiments are however separated by two generations of selfing

TABle 2

Classification of the derivatives of CS monosomic $5 D \times\left\{C S D T 5 D^{L} \times C S\right.$ (Hope $\left.\left.5 D\right)\right\}$

$\begin{array}{lcccccc}\text { Ear-emergence class } & \overbrace{\begin{array}{c}\text { Late } \\ \text { Complete }\end{array}}^{\text {Chromosome type }} & \begin{array}{c}\text { Early } \\ \text { Telocentric }\end{array} & \overbrace{\begin{array}{c}\text { Late } \\ \text { Telocentric }\end{array}}^{\text {Non-recombinants }} & \begin{array}{c}\text { Early } \\ \text { Complete }\end{array} & \text { Total } \\ \text { Experiment 1 and 2 } & 8 & 4 & - & 13 & 25 \\ \text { Experiment 3 } & 61 & 3 & 1 & 53 & 118 \\ \text { Total } & 69 & 7 & 1 & 66 & 143\end{array}$

Late $v$. early $\chi_{\{1\}}^{2}=0.06, \mathrm{P} 0 \cdot 9-0 \cdot 8$

Complete $v$. telocentric $\chi_{\{1\}}^{2}=112.79, \mathrm{P}<0.001$

Linkage $\chi_{\{1\}}^{2}=0 \cdot 57$, P $0 \cdot 5-0 \cdot 3$ 
so that if the gene is located on another chromosome than $5 \mathrm{D}$ there would have been some opportunity for segregation. On the other hand, if the gene is situated on chromosome $5 \mathrm{D}$, segregation could not have occurred during the two selfed generations that separate the two experiments. The level of agreement between the two experiments therefore provides a test of the location of this gene.

The behaviour of the related lines in the two experiments is shown in fig. 1 and indicates that the early and late classification of the first experiment is exactly reproduced in the second. The gene must therefore be on chromosome $5 \mathrm{D}$ and must, because of the segregation from the cross involving the long-arm telocentric, be located on this arm of the chromosome.

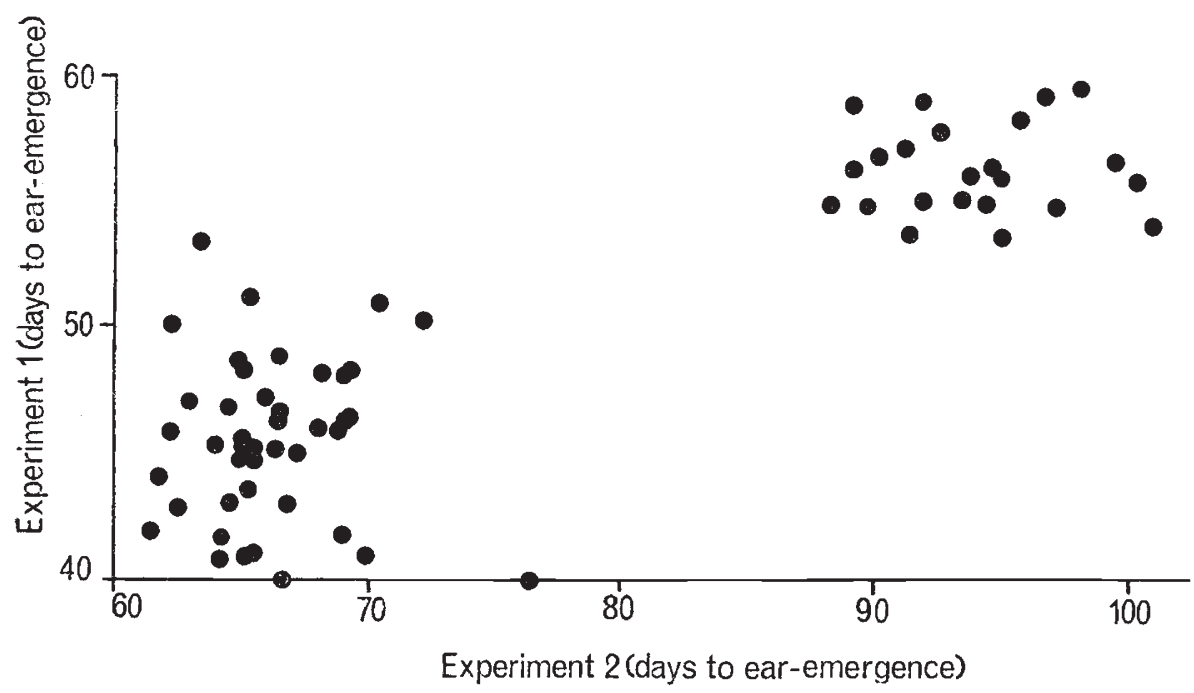

Fig. 1.-The relationship between the mean ear-emergence scores for families grown in the field (Experiment 1) and in a controlled environment (Experiment 2).

Because of the small numbers involved in determining the position of this gene on the long arm, further derivatives of CSDT 5DL $\times$ CS (Hope 5D) were grown in the glasshouse during the winter of 1971. In all 118 plants were classified as early or late and as having the complete or telocentric chromosome in the hemizygous condition. The segregation into the four possible classes are shown in table 2. A good agreement occurs between the segregation pattern obtained and the derivatives studied in experiment I and 2. Combining both sets of data gives an estimate of the recombination value between the gene and the centromere of $p=0 \cdot 469 \pm 0 \cdot 041$. The gene segregates independently, therefore, of the centromere and is obviously distally located on the long arm of chromosome 5D.

Examination of chiasma at metaphase $I$ of meiosis in the hybrids, CSDT 5DL $\times$ CS (Hope 5D), gave a mean frequency of $1.80 \pm 0.06$ chiasmata for the long arm of chromosome 5D. This indicates a genetic map for this arm of approximately 90 map units. The gene affecting ear-emergence time is therefore situated somewhere within the distal 40 units of this chromosome arm. 
(ii) The investigation of chromosome $5 \mathrm{~A}$

A similar experiment was carried out on the substitution line, CS (Hope 5A). In contrast to CS (Hope 5D), this line is much earlier in ear-emergence time than GS.

CS(Hope 5A)

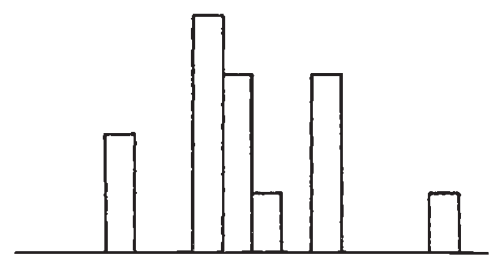

CS
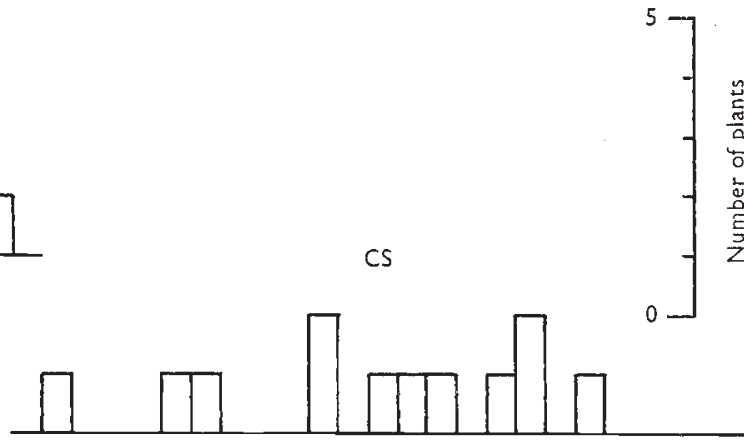

$\mathrm{CS} \times \mathrm{CS}($ Hope 5A)
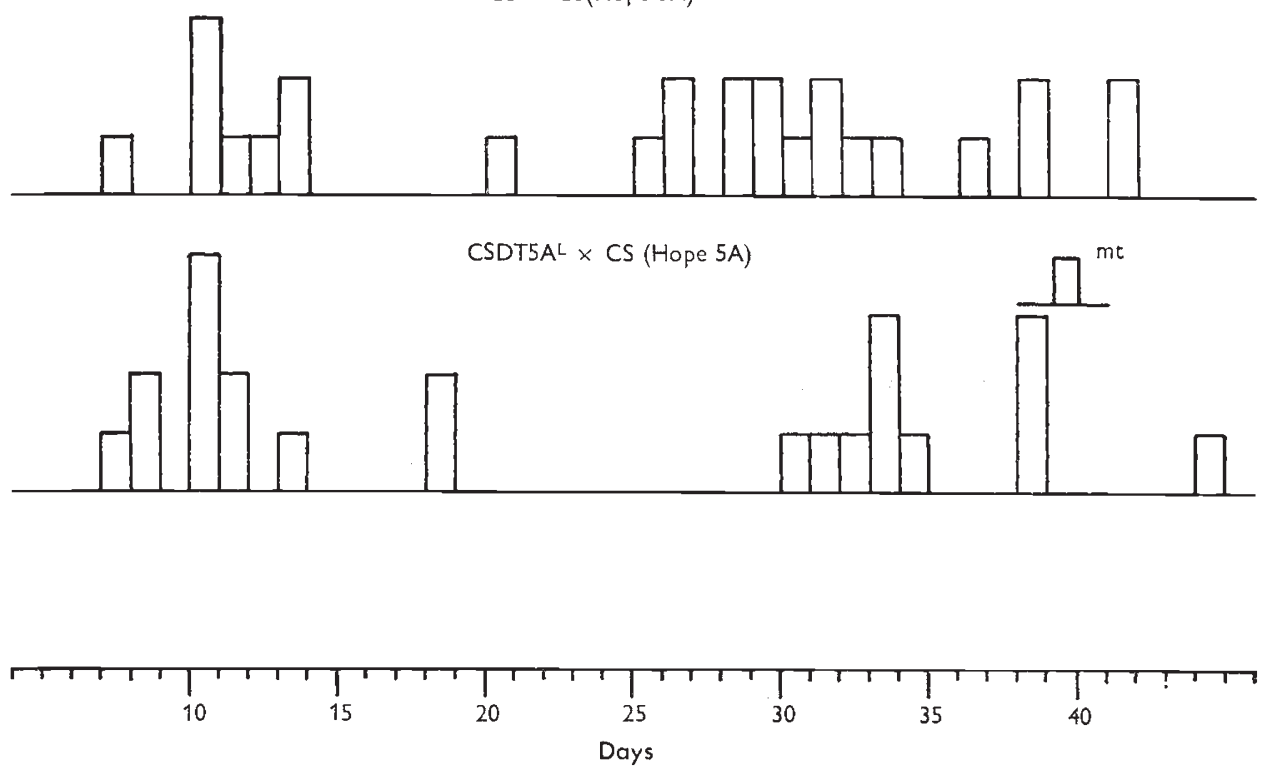

FIG. 2.-Ear-emergence scores of monosomic plants obtained by crossing Chinese Spring (CS) and CS (Hope 5A), and the hybrids, CS $\times$ CS (Hope 5A) and CSDT 5A ${ }^{L} \times$ CS (Hope 5A) on to monosomic 5A of CS. The scores refer to the number of days to ear emergence from an arbitrary date. $\mathrm{mt}=$ mono-telocentric.

In this experiment, 26 derivatives of $\mathrm{CS} \times \mathrm{CS}$ (Hope 5A) and 25 derivatives of CSDT $5 \mathrm{~A}^{\mathrm{L}} \times \mathrm{CS}$ (Hope $5 \mathrm{~A}$ ) crossed to $\mathrm{CS}$ monosomic $5 \mathrm{~A}$, as well as 14 and 12 derivatives respectively from CS (Hope 5A) and CS crossed to the monosomic were grown in a controlled environment room under conditions similar to those obtaining in the investigation of chromosome $5 \mathrm{D}$. All the 
derivatives were scored for their days to ear emergence and the analysis was confined to monosomic or mono-telocentric plants identified by the speltoid nature of their spikes, a character associated with the monosomic condition of this chromosome (Sears, 1954).

The results of this experiment are given in fig. 2. For the derivatives of CS $\times$ CS (Hope 5A) there is a strong suggestion of a segregation into two classes of early and late. Also the mean (20.3) and variance (4.4) of the derivatives of CS and CS (Hope 5A) combined and the mean (24.9) and variance (4.5) of the CS $\times$ CS (Hope $5 \mathrm{~A}$ ) derivatives are indistinguishable from each other, so that the variation can be explained in terms of the segregation at a single locus.

Two distinct classes are also evident among the derivatives of GSDT $5 \mathrm{~A}^{\mathrm{L}} \times \mathrm{CS}$ (Hope $\left.5 \mathrm{~A}\right)$. The full classification of these derivatives, including the segregation of the telocentric or complete chromosome, based upon chromosome counts of the progeny of these plants, are given in table 3.

TABLE 3

Classification of the derivatives of CS monosomic $5 A \times\left\{C S D T 5 A^{L} \times C S(\right.$ Hope $\left.5 A)\right\}$

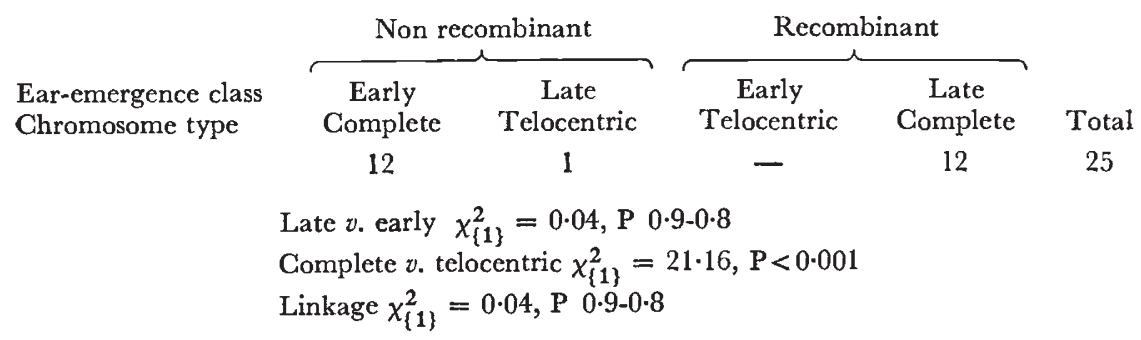

The $\chi^{2}$ 's testing this segregation, support the hypothesis of a single gene, low transmission of the telocentric chromosome and the absence of linkage between the gene and the centromere $(p=0.48 \pm 0.09)$. The lack of segregation among the derivatives of CS (Hope 5A), however, indicates that the gene must be located on chromosome $5 \mathrm{~A}$ despite its independent segregation with the centromere of this chromosome.

A very similar picture therefore emerges from the studies of chromosomes $5 \mathrm{~A}$ and $5 \mathrm{D}$. In each case a single gene, having a large effect on ear-emergence time, can be located on the long arm of both homoeologous chromosomes. Furthermore, the centromere-recombination values are not different from independence, so that both genes are located distally and at distances in excess of 50 map units from the centromere.

(iii) The investigation of $5 A$ and $5 D$ chromosomes from other sources

A number of CS lines having either chromosome 5A or 5D substituted from a range of varieties was studied in order to determine the extent of the variation that can occur among these chromosomes. Included in this study were the substitution lines, CS $5 \mathrm{~A}(5 \mathrm{Cu})$ and $\mathrm{CS} 5 \mathrm{D}(5 \mathrm{Cu})$, in which $5 \mathrm{Cu}^{\mathrm{u}}$ from Ae. umbellulata replaces either 5A or 5D of CS.

The mean ear-emergence scores for each of these substitution lines obtained from replicated plants grown for 5 weeks under continuous light at $18^{\circ} \mathrm{C}$ in a controlled environment cabinet and then in a glasshouse are 
given in Table 4. The scores for the 5D substitution lines can be classified into a late group, composed of CS (Hope 5D), CS (Cheyenne 5D), CS (Cappelle-Desprez 5D) and CS 5D (5Cu), and CS and CS (T. spelta 5D). For the $5 \mathrm{~A}$ substitution lines, the number of groups is slightly larger, CS (Cappelle-Desprez 5A), CS (Cheyenne 5A) and CS 5A (5Cu) forming one group, whereas CS, CS (Hope $5 \mathrm{~A}$ ) and CS ( $\mathcal{T}$. spelta $5 \mathrm{~A}$ ) give mean earemergence values which are different from each other. A wide range of variation therefore exists for both sets of substitution lines and it is possible that this could be due to allelic differences at the locus identified on Hope $5 \mathrm{~A}$ and that on Hope 5D.

\section{TABLE 4}

Differences between the mean ear-emergence values for substitution lines of chromosomes $5 D$ and $5 \mathrm{~A}$ and the mean values of Chinese Spring (CS) and the alien chromosome substitution lines, $C S 5 D\left(5 C^{u}\right)$ and $C S 5 A\left(5 C^{u}\right)$

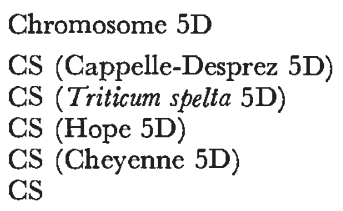

\section{Chromosome 5A}

CS (Cappelle-Desprez 5A)

CS (Triticum spelta $5 \mathrm{~A}$ )

CS (Hope 5A)

CS (Cheyenne 5A)

CS

$$
\begin{aligned}
& \text { Difference from } \\
& \mathrm{CS}=79.0 \\
& +13.0 * * \\
& +3 \cdot 5 * \\
& +11 \cdot 0 * * \\
& +11 \cdot 0 * * \\
& \text { - } \\
& \uparrow \operatorname{LSD}\left(\mathrm{P}_{0.05}\right) 3.08 \\
& \text { Difference from } \\
& \mathrm{CS}=79.0 \\
& +4.8 * * \\
& -17 \cdot 3 * * \\
& -12 \cdot 3 * * \\
& +1 \cdot 8 \\
& \uparrow \operatorname{LSD}(\mathrm{P} 0.05) 3.08 \\
& \text { CS } 5 \mathrm{D}\left(5 \mathrm{C}^{\mathrm{u}}\right)=92 \cdot 3 \\
& -0.3 \\
& -9 \cdot 9 * * \\
& -2 \cdot 3 \\
& -2 \cdot 3 \\
& -13 \cdot 3 * * \\
& \text { Difference from } \\
& \text { CS } 5 \mathrm{~A}\left(5 \mathrm{C}^{\mathrm{u}}\right)=82 \cdot 0 \\
& +1.8 \\
& -20 \cdot 3 * * \\
& 15 \cdot 3 * * \\
& -1 \cdot 3 \\
& -3 \cdot 0 * \\
& \dagger \operatorname{LSD}(\mathrm{P} 0.05) 2.73
\end{aligned}
$$

* $\mathrm{P} 0.05-0.01 * * \mathrm{P}<0.01$.

$\dagger$ The different LSD values arise from unequal plant numbers for the CS, CS $5 \mathrm{~A}\left(5 \mathrm{C}^{\mathbf{u}}\right)$ and $\mathrm{CS} 5 \mathrm{D}\left(5 \mathrm{C}^{\mathrm{u}}\right)$ genotypes.

An interesting feature of these results is the equivalence between the effects of some of the substituted chromosomes of $5 \mathrm{~A}$ and $5 \mathrm{D}$ with the effect of $5 \mathrm{Cu}$ of Ae. umbellulata. Because $5 \mathrm{Cu}$ is common to both the $5 \mathrm{~A}$ and $5 \mathrm{D}$ sets of substitution lines, it is possible to relate the variation among the $5 \mathrm{~A}$ chromosomes to the variation exhibited by chromosome $5 \mathrm{D}$. Thus the effects of Cappelle-Desprez 5A and Cheyenne 5A must be equivalent to Cappelle-Desprez 5D, Hope 5D and Cheyenne 5D simply because of their equivalence to $5 \mathrm{Cu}$.

It is not possible however to relate the remaining chromosomes of $5 \mathrm{~A}$ and $5 \mathrm{D}$. It is obvious that $\mathrm{CS} 5 \mathrm{D}$ has an effect for extreme earliness, whereas this is not the case for CS 5A. Also it is likely that the early effects of Hope 5A and $T$. spelta $5 \mathrm{~A}$ are similar to the effect of CS 5D. By intercrossing the lines carrying these chromosomes, or by comparing their effects with another alien chromosome, it may be possible to establish these relationships more precisely. 


\section{Conclusion}

The single loci located on each of the distal parts of the long arms of the homoeologous chromosomes $5 \mathrm{~A}$ and $5 \mathrm{D}$ of Hope, combined with the information that these two chromosomes interact in a duplicate manner (Law, 1972), provide strong evidence that the loci are identical and can be regarded as a duplicated gene system resulting from the polyploid nature of wheat.

Although the genes on CS (Hope 5A) and CS (Hope 5D) have not been tested for their effect on vernalisation treatment, the extreme sensitivity of each of these substitution lines to vernalisation treatment (Halloran and Boydell, 1967), almost certainly indicates that it is the genes, affecting ear emergence in the experiments reported here, which are responsible. The sensitivity of the other substitution lines for chromosomes $5 \mathrm{~A}$ and $5 \mathrm{D}$ to vernalisation has also been confirmed in experiments carried out in this laboratory (Law, 1973).

Pugsley (1972) has identified four genes affecting vernalisation requirement and has designated these as $V r n_{1}$ to $V r n_{4}$. $V r n_{1}$ has been equated with a spring growth habit gene, recognised first by Ackerman and Mackey (1949) and subsequently located by Mackey (1954) and Tsunewaki (1966) on chromosome 5A. $V r n_{1}$ is therefore likely to be identical to the gene located on Hope 5A.

Pugsley (1972) has also indicated that the spring growth habit of CS is determined by a single dominant gene for vernalisation response, $V r n_{3}$. Since nullisomic $5 \mathrm{D}$ of GS is the only nullisomic to give both winter habit and extreme lateness in ear emergence (Sears, 1954), then $V r n_{3}$ must be located on 5D and is likely to be the gene identified in CS (Hope 5D). Vrn and $\mathrm{Vrn}_{3}$ may therefore be positioned distally on the long arms of chromosomes $5 \mathrm{~A}$ and $5 \mathrm{D}$ respectively.

The chromosomal locations of $V r n_{2}$ and $V r n_{4}$ have still to be established but a single locus, at the moment designated $V r n_{5}$, affecting ear emergence and causing sensitivity to vernalisation, was located by Law $(1967,1968)$ on the short arm of chromosome $7 \mathrm{~B}$ of Hope. It is possible that this may be eventually equated with one of the two remaining loci identified by Pugsley.

The study of the other substitution lines has revealed additional variation over and above that contributed by chromosomes $5 \mathrm{~A}$ and $5 \mathrm{D}$ of Hope and CS. This could result from a multiple allelic series at the $V r n_{1}$ and $V r n_{3}$ loci. Also, the use of an alien chromosome, $5 \mathrm{Cu}$ of $\mathrm{Ae}$. umbellulata as a control, has permitted the recognition of equivalence between the effects of CappelleDesprez 5A and Cheyenne 5A and Cappelle-Desprez 5D, Hope 5D and Cheyenne 5D. If the hypotheses of multiple allelism at each of identical loci, $V r n_{1}$ and $V r n_{3}$, proves correct, then all these chromosomes must also carry the same allele even though they occur on different homoeologues.

Although further work is necessary to substantiate this hypothesis, the variation in ear-emergence time among the $5 \mathrm{~A}$ and $5 \mathrm{D}$ chromosomes indicates that a wide range of genotypes is possible. At the moment the range of responses that these genotypes can produce under either winter or spring sown environments is not known. Presumably within each of these major environmental groupings a range of differing environments can occur. The large number of possible genotypes suggests that close adaptation can be achieved, over and above the extreme adaptations exhibited by winter and spring wheats. 


\section{REFERENGES}

AKERMAN, A., AND MACKEY, J. 1949. Efforts to increase yield of spring wheat. II. Crosses between spring and winter wheats: description of Svälot Ello spring wheat. Sveriges Utsädesfar. tidskr., 59, 105-117.

halloran, G. M. 1966. Gene dosage and character expression in bread wheat. $\mathcal{J}$. Aust. Inst. Agr. Sci., 32, 228-229.

HALLORAN, G. M., AND BOYDELL, c. w. 1967. Wheat chromosomes with genes for vernalization response. Can. 7. Genet. Cytol., 9, 632-639.

KUSPIRA, J., AND UNRAU, J. 1957. Genetic analysis of certain characters in common wheat using whole chromosome substitution lines. Can. 7. Plant Sci., 37, 300-326.

LAW, c. N. 1966. The location of genetic factors affecting a quantitative character in wheat. Genetics, 53, 487-498.

LAW, c. N. 1967. The location of genetic factors controlling a number of quantitative characters in wheat. Genetics, 56, 445-46I.

LAw, c. N. 1968. Genetic analysis using inter-varietal chromosome substitutions. Proc. 3rd Int. Wheat Genet. Symposium, Canberra, 331-342.

LAW, C. N. 1972. The analysis of inter-varietal chromosome substitutions in wheat and their first generation hybrids. Heredity, 28, 169-179.

LAw, c. N. 1973. Annual Rep. Plant Breeding Institute, 1972, pp. 128-129.

MACKEY, J. 1954. Neutron and X-ray experiments in wheat and a revision of the speltoid problem. Hereditas, 40, 65-180.

MAYSTRENKO, O. I. 1974. Identification of chromosomes carrying genes $V m_{1}$ and $\mathrm{Vrn}_{3}$ inhibiting winter habit in wheat. European Wheat Aneuploid Newsletter, 4, 49-52.

MORRISON, J. W. 1960. The monosomic analysis of growth habit in winter wheat. Z. Vererb., 91, 141-I51.

Pugsley, A. T. 1971. A genetic analysis of the spring-winter habit of growth in wheat. Aust. 7. Agric. Res., 22, 21-31.

PUGSLEY, A. T. 1972. Additional genes inhibiting winter habit in wheat. Euphytica, 21, 547-552.

RAJKI, E., AND RAJKI, s. I969. Monosomic analysis of growth habit in autumnization process. Proc. 5th Eucarpia Congress, Milan, 43-46.

SEArs, E. R. 1954. The aneuploids of common wheat. Missouri Agric. Exp. Sta. Res. Bull., No. 572 , pp. 59.

TSUNEWAKI, K. 1966. Comparative gene analysis of common wheat and its ancestral species. II. Waxiness, Growth Habit and Awnedness. Jap. 7. Bot., 19, 175-229.

UNRAU, J. 1950. The use of monosomes and nullisomes in cytogenetical studies of common wheat. Sci. Agric., 30, 66-89. 